\section{Free intraperitoneal air on paediatric plain radiographs and differentiating this from a 'food mound'}

S Andronikou
MBBCh (Wits), FCRadDiag (SA), FRCR (London)
C Welman
MBChB
E Kader
MBChB
low viscus. These may be differentiated by their clinical setting. On occasion a child with a perforated viscus may show pneumoperitoneum on radiographs, but have none of the classical features of an acute abdomen clinically. ${ }^{1,2}$ It is in such situations that the surgeon may rely on the radiolo-

is especially so when noted on the right above the liver (Figure 1), but also when situated between the diaphragm and stomach (Figure 2). ${ }^{1}$

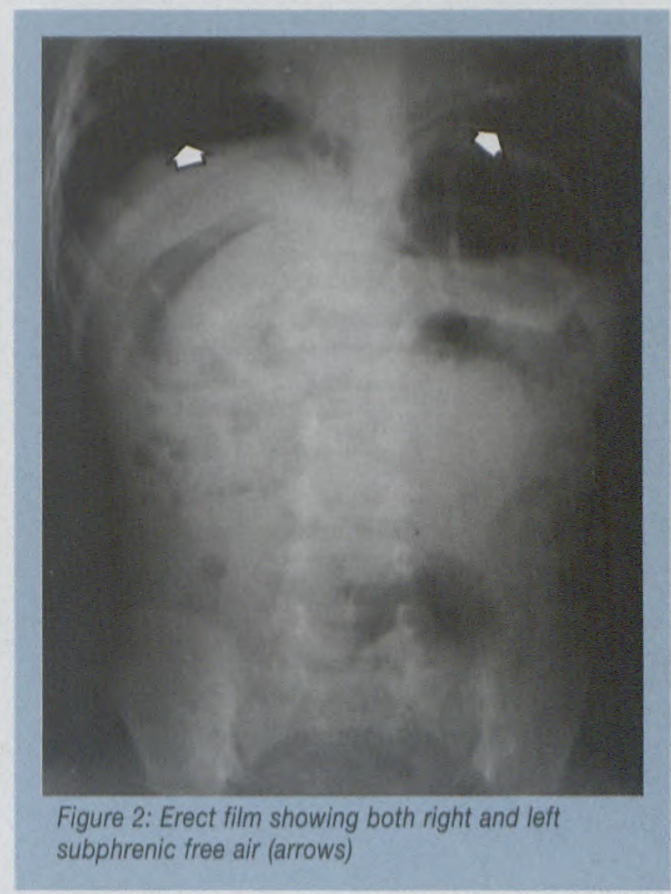

More difficult is the detection of free air on a supine film where air may present around the falciform ligament (Figure 3 ) or in the subhepatic space gist's findings. There are also situations

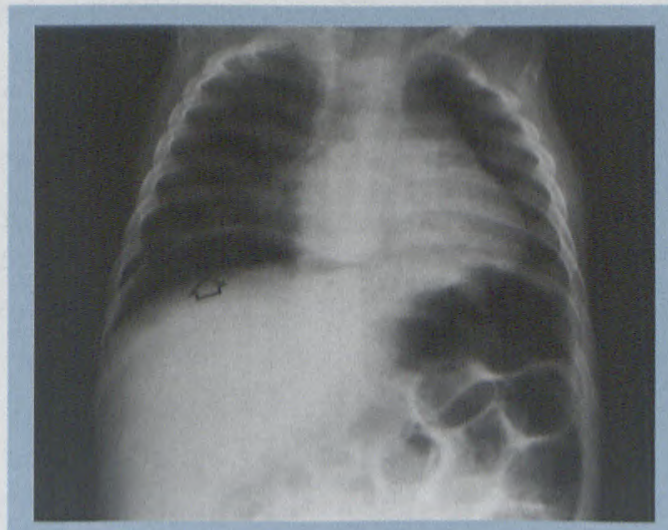

Figure 1: Erect film showing right subphrenic free air (arrow) where pneumoperitoneum is seen as a surprise finding on chest radiographs performed for intrathoracic disease (e.g. pneumomediastinum).

The best known Xray finding of free intraperitoneal air is free subphrenic air seen on an erect chest film. This

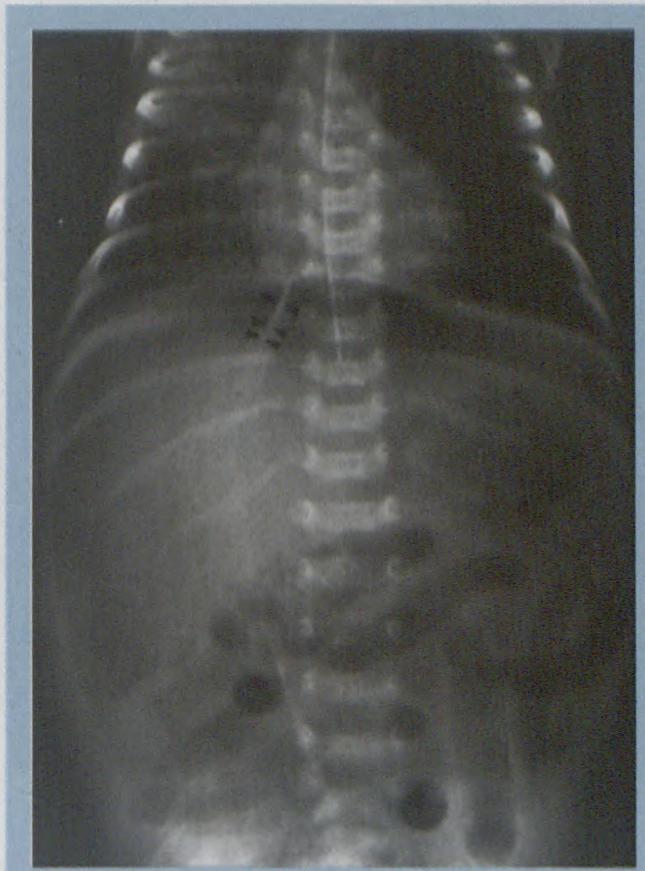

Figure 3: Supine film with free air outlining the falciform ligament (arrowheads) 
Free intraperitoneal air on paediatric plain radiographs and differentiating this from a 'food mound'

\section{from page 29}

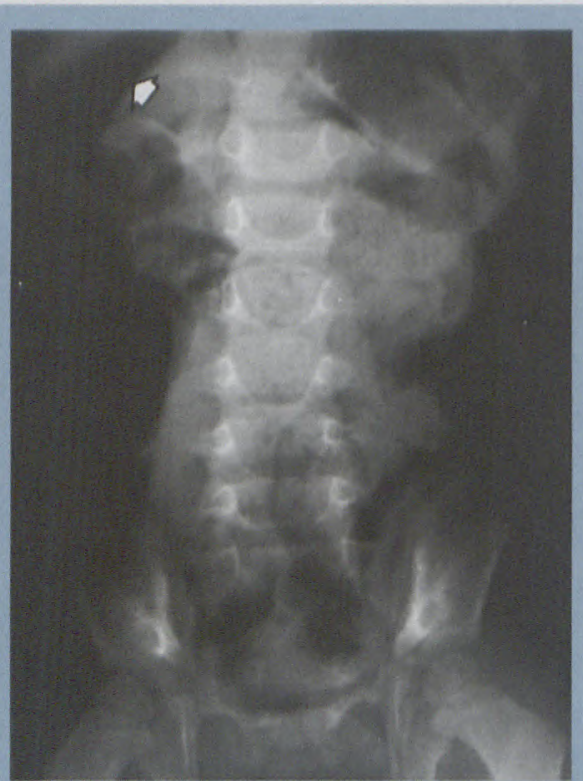

Figure 4: Free air at the subhepatic space (arrow)

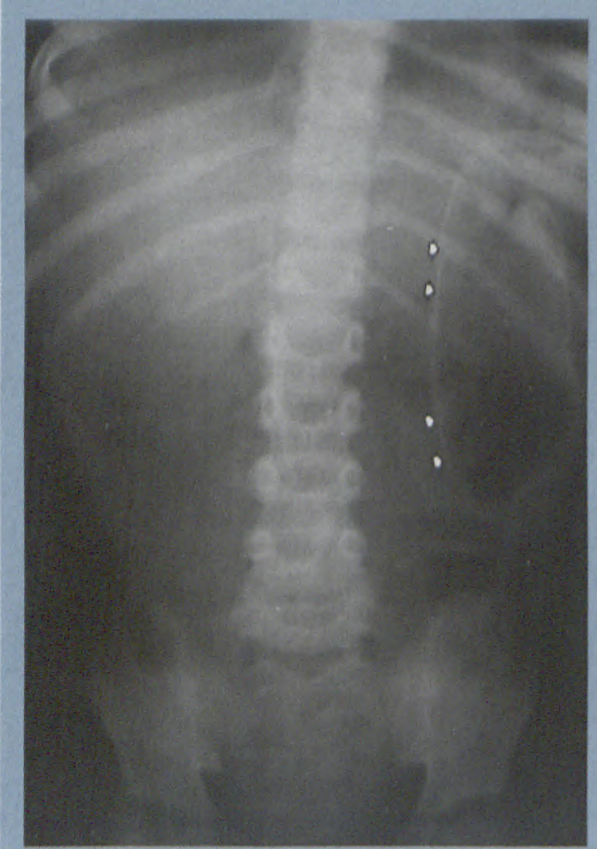

Figure 5: The "Rigler's" sign, with air outlining both sides of the bowel wall (arrows)

(Figure 4) or may delineate both sides of the bowel wall as the "Rigler's sign" (Figure 5). ${ }^{1,2}$ Larger volumes of air may be seen as the "lucent liver sign" (Figure 6) and small children may show large amounts of free intraperitoneal air as the "football" sign (Figure 7). ${ }^{1}$ A decubitus film with the right side up (Figure 8) and a hori-

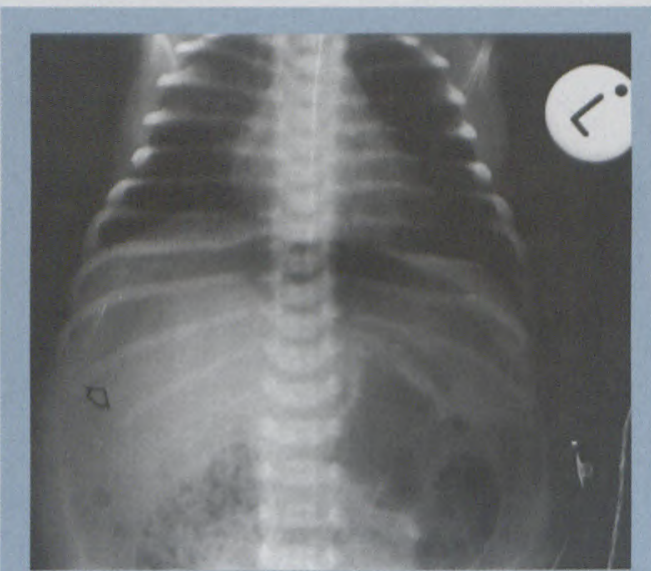

Figure 6: Supine film showing the "lucent liver" sign (arrow)

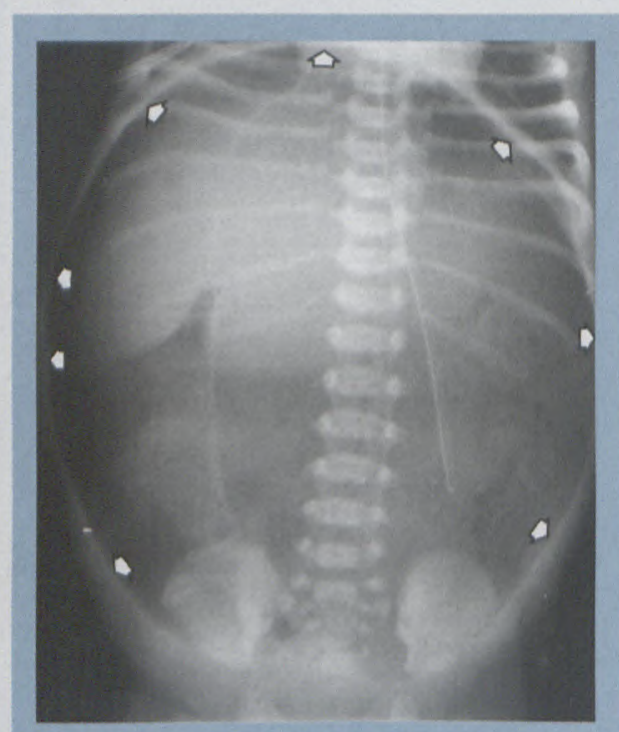

Figure 7: Supine film of a neonate showing free air as the 'football' sign (arrows)

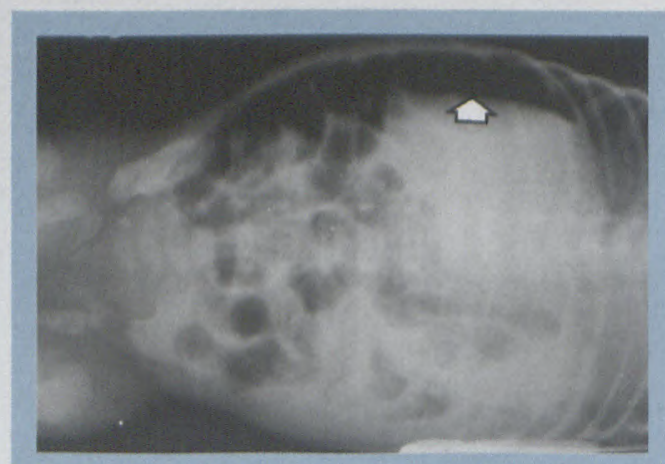

Figure 8: Lateral decubitus film with the right side up, showing free air around the lateral aspect of the liver (arrow)

zontal beam shoot-through (Figure 9) are useful techniques for identifying free air, ${ }^{1,2}$ especially in the ICU setting.

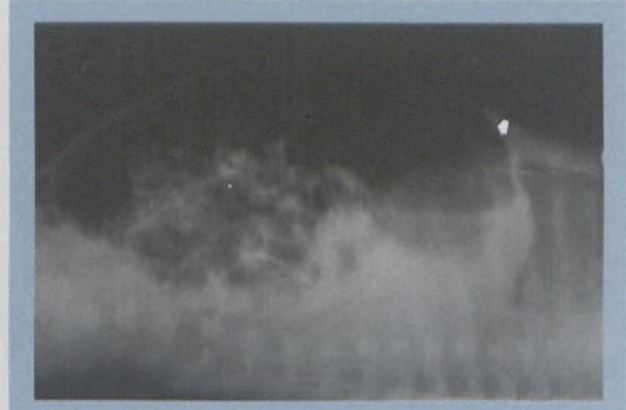

Figure 9: Horizontal beam supine film shows the free air just deep to the anterior surface with a visible "Rigler's" sign (arrow)

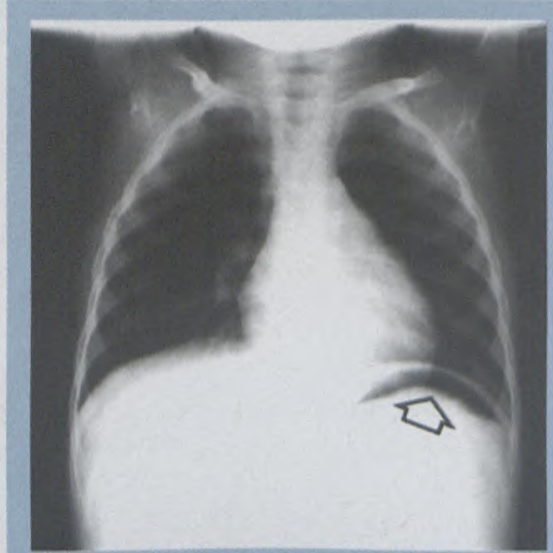

Figures 10 (above) and 11 (below): The "food mound" sign simulating a left subphrenic collection of free intraperitoneal air (arrow)

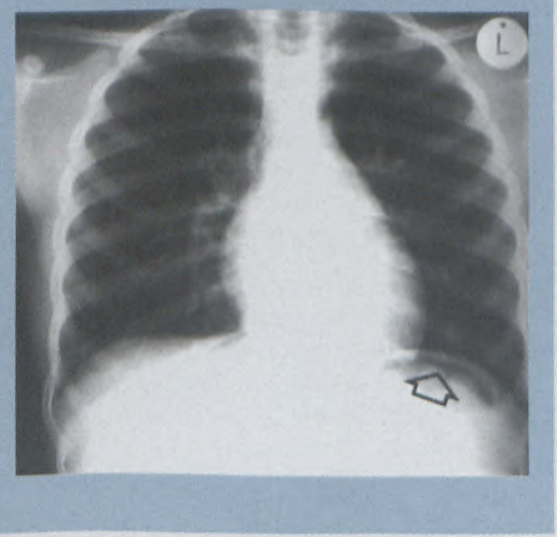

Every so often we are shown a radiograph like Figures 10 or 11, where there is suspicion of free air under the left hemidiaphragm. These radiographs are deceptive in the erect position, as a specific food type or consistency may result in what we have termed the "food mound" sign. Food 